\title{
Investigating the Compressive Strength Properties of Concrete Using Some Common Ghanaian Ordinary Portland Cements
}

\author{
Akorli, K. S. ${ }^{1}$, Danso, K. ${ }^{2}$, Ayarkwa, ${ }^{3}$. and Acheampong, $\mathrm{A}^{4}$. \\ 1, 2, 3نs. Department of Construction Technology and Management, College of Art and Built Environment Faculty of Built \\ Environment. Kwame Nkrumah University of Science and Technology. Kumasi \\ ${ }^{1 *}$ Correspondence: soking1975@yahoo.com
}

Abstract

In a general sense, concrete is made of cementitious material, aggregates and water but the mix productivity is one issues that affect the amount of strength concrete developed. The concrete mix productivity is a direct function of the amount and quality of the cementitious material. The commonest cementitious material used for concrete in Ghana like other countries in the world is the Ordinary Portland Cement. The research sort to investigate the compressive strength properties of concrete made from some common Ghanaian Ordinary Portland Cement brands mostly used in the countries construction industries. The research strategy adopted was experimental. The research was a cross -sectional studies and used laboratory tests to get information on all cements. Cement grade 42.5N, 42.5R and 32.5R were used. A total of one - hundred and eight (108) concrete cubes were made from nine different brands of Ordinary Portland Cement with a mix design of 1:2:4. No admixtures were used in the mix. It was established that, Ordinary Portland Cement Brand E of grade 42.5R has the highest compressive strength after 28 days. Some of the cement brand with grade 32.5R developed better strength than that of grade 42.5R. Based on the experiment conducted, it can be concluded that for the C15 (1:2:4) and C20 compressive strength as per IS 456:2000, Ordinary Portland Cement Brand E and G of grade 42.5R and Ordinary Portland Cement Brand H and J of grade of 32.5R satisfactory meets the requirement. It implies that some of the Ghanaians Portland Cement developed a satisfactory compressive strength and meets the minimum strength attainment after 28 days' which is $15 \mathrm{~N} / \mathrm{mm}^{2}$. Based on the result, it is recommended that Ordinary Portland Cement Brand E of grade 42.5R should be used for most concrete production and Ordinary Portland Cement Brand J of grade 32.5R can also be used for concrete work in the absence of E 42.5R.

Keywords: ordinary portland cement, concrete, compressive strength, rate of strength, age

Citation: Akorli, K. S., Danso, K., Ayarkwa, J. and Acheampong, A. (2021). Investigating the Compressive Strength Properties of Concrete Using Some Common Ghanaian Ordinary Portland Cements. International Journal of Technology and Management Research (IJTMR), Vol. 6 (1): Pp.154-166.

Received: March 13, 2021

Accepted: September 1, 2021 


\subsection{Introduction}

According to Ali et al. (2008) any cement to be used in construction work must have some particular traits to make it play its part successfully in the construction. Ali et al. (2008), continue that, when the cement properties lays within a certain standard specified range values, it gives users the assurance that the cement will be able to give a suitable perform very well when used in any construction works. Ali et al. (2008), believed that based on the cement properties it is conceivable to compare the quality of cement from different sources.

In terms of concrete, cement is a fine grinded powder which consists of alumina, silica, lime, iron oxide, and magnesium oxide burned together in a kiln and used as an ingredient of mortar and concrete; it can be any mixture used for a similar purpose in construction. Cement is the most used construction material in the world since it is a very adaptable material, with amazing mechanical properties and chemical durability (Manzano, et al., 2011). According to Ali et al. (2008) every year massive quantity of Ordinary Portland Cement (OPC) is produced and used for the construction of infrastructure for development in the world. Ali et al. (2008), have found out that in Bangladesh, the use of poor-quality cement in structural works causes loss of lives and properties.

The Ghanaian's construction industry depends massively on Portland cement for almost infrastructure development in the country. The infrastructure development by construction industry greatly depends on Ordinary Portland Cement in the country. In 2014 it was estimated that nearly four million tonnes of ordinary Portland cement were consumed and the consumption is predicted to increase a record of about five million tonnes by 2020 (Bediako and Amankwah, 2015)

In the Republic of Ghana, the cement industry was controlled by Ghana Cement Manufacturers (Ghacem) for some years. Importation of cement from other part of the world like China, India and western Europe countries has broken the supremacy of Ghacem. There is an invasion of Ghanaian cement market recently with a lot of new cement brands. The introduction of this new cement onto the market has generated an augment whether these new types of Ordinary Portland Cement can attain adequate strength to Engineers specification (Bediako and Amankwah, 2015). According to Salih et al. (2020) one of the limitation that impact the performance of concrete is the compressive strength of cement. Salih et al. (2020) believed that the chemical composition and the physical properties of ordinary Portland cement can be significantly affected its compressive strength.

This research is to ascertain whether all Ordinary Portland Cement brands found in Ghana, can attain the same compressive strength when used in concrete production.

\subsection{Concrete and its Compressive Strength}

Concrete as a compound consist of cement, water, fine aggregate and coarse aggregate with or without admixture (Lee et al., 2020). Ni and Wang (2000) see concrete as an artificial material formed by correct mixing of cement, coarse aggregate, such as gravel, fine aggregate, such as sand, with acceptable and controlled amount of water. According to Ni and Wang (2000) experience has shown that if some parameters of the fresh concrete, such as the grade of cement, the water/cement ratios, quantity of cement, quantity of water and slumps, within specified limits, are controlled, the long -term properties of the concrete can be improved. 
Concrete is the most important structural compound used widely in the construction industry (Salih et al., 2020). The richness of a concrete mix depends on the quantity and quality of the binding agent used in the production (Hewlett and Liska, 2019).

According to De-Schutter and Lsesage, (2018) the quality and performance of concrete as a building material depend on the mix design, the processing and the manufacturing. The type, quality and quantity of basic materials are key elements in view of gaining the correct concrete for the right job. De-Schutter and Lsesage, (2018) believed that quality control accordingly is an important aspect in concrete industry, that involves quality control of the component materials, quality control of the mixing process, quality control during execution, and quality control of the final properties. According to Hasan and Kabir (2011) concrete is preferable available, comparatively cheap, flexible to handle and it gives shape and any anticipated form. Hasan and Kabir (2011), opined that the most acute property that gives general idea of a very good quality concrete is the compressive strength. The strength property of concrete is a frequently investigated because it gives a good sign of a complete quality concrete (Khoury, 1992). Compressive strength of concrete is a generally known measure to access the performance of a given concrete mixture. This feature of concrete is important because it is the key measure that determines how well concrete can withstand loads. The accuracy of the compressive strength tells whether or not a specific mix design is suitable to meet the requirements of exact project.

$\mathrm{Ni}$ and Wang (2000) see compressive strength of concrete as a chief and significant mechanical property, which is commonly obtained by measuring concrete specimen after 28days normal curing.

The strength of concrete is believed to be developed by the standardised bonding force of each component, and the primary powerful factor of the concrete strength development is the cement (Lee et al., 2020).

Adewole, et al. (2015) have found out that, using a cube side of $150 \mathrm{~mm}$ to produced concrete for test; the compressive strength of the cube at the age of 28 days when tested must vary between $15 \mathrm{~N} / \mathrm{mm}^{2}$ to $80 \mathrm{~N} / \mathrm{mm}^{2}$. CivilSir (2015) found out that for design mix of 1:2:4 (M15), the minimum strength to attain in 28 day's age should be $15 \mathrm{~N} / \mathrm{mm}^{2}$.

According to Hemali (2018) the common factors that affects concrete compressive strength are: type of cement, amount and quality or brand of cement, unintentional replacement of cement, cleanness and grading of the aggregates, water/cement ratio, handing and placement methods, temperature, mixing and curing conditions and the likes.

"The compressive strength of any material is defined as the resistance to failure under the action of compressive forces" (Anand, 2016). According to Anand (2016), compressive strength of concrete is the main parameter to determine the performance of the material during its service conditions. The compressive strength of concrete is specified in terms of the characteristic compressive strength of $150 \mathrm{~mm}$ size cubes tested at 28 days (Anand, 2016). So many researches have been done to compare different grade of cement's compressive strength.

Mathur et al (2014) reported from India that concrete produced with ordinary Portland cement and fly ash- baese Portland pozzolana cement grade 42.5 and 52.5 produces differences in properties. In Egypt, Hodhod and Abdeen (2010) conducted a relative study on the properties of concrete made with OPC grades 52.5, 42.5 and 32.5 and 
reported differences in their properties. Kazeem, et al (2014) reported from Nigeria that in a comparative study of compressive strength of concrete made with grade $42.5 \mathrm{~N}$ and $32.5 \mathrm{~N}$ the result show difference in the compressive strength at 28 days' age.

\subsection{Methodology}

\subsection{Materials}

Ordinary Portland Cement (OPC) from different manufactures were used. The grade of cement used were 32.5N, 32.5R and 42.5R table 1 below. The coarse aggregate used was $20 \mathrm{~mm}$ maximum size crushed granite. Admixtures or additives were not used in this work. Nearby available pit sand aggregate was used in accordance with BS 882:1992 and BS 8500-2:2002.

Table 1: Coding of Ordinary Portland Cement

\begin{tabular}{l|l|l}
\hline No & Ordinary Portland Cement Brand & Grade \\
\hline 1 & DANGOTE & $42.5 \mathrm{R}$ \\
2 & WP SOL & $32.5 \mathrm{R}$ \\
3 & CIMAF & $42.5 \mathrm{~N}$ \\
4 & GHACEM & $32.5 \mathrm{R}$ \\
5 & SOL CEMENT & $42.5 \mathrm{R}$ \\
6 & SUPACEM & $42.5 \mathrm{R}$ \\
7 & GHACEM & $42.5 \mathrm{R}$ \\
8 & DIAMOND & $32.5 \mathrm{R}$ \\
9 & SUPACEM & $32.5 \mathrm{R}$ \\
\hline
\end{tabular}

In all one - hundred and eight (108) concrete cubes were made from nine different brands of Ordinary Portland Cement found in Ghanaian construction industry. Ghana Feeder Road Laboratory in Koforidua was selected for the experiment; since all the necessary materials, equipment and machines can be found there.

\subsection{Mix Proportion}

In order to measure strength properties, a mix ratio of 1:2: 4 of cement, fine aggregates and coarse aggregates with a water/cement ratio of 0.5 was used for the concrete production in accordance with GBC 2012, BS 8500 and BS EN 206. The materials were weighed using the weighing scale machine. Mixing of the concrete was done by hand. In other to ascertain compressive strength development of various cement brands, the proportioning of the materials was constant, accept the different cement brand used. 


\subsection{Designation and preparation of Specimens}

For specimens of nine group, one-hundred and eight $150 \mathrm{~mm} \times 150 \mathrm{~mm} \times 150 \mathrm{~mm}$ concrete cubes were produced for the 7-day, 14-day, 21day and 28day, compressive strength tests at three cubes for each curing period. The cubes were labelled as A1 - A12 to J1 to J12

The mould boxes were removed after twenty - four (24) hours for curing. All the cubes were put into a curing reservoir containing water. The cubes remain in the water till the end of 28 days. The cubes were tested at Ghana Feeder Road Laboratory in Koforidua. The load was recorded. Based on the load causing the failures of the cubes and the strength of the concrete cubes were calculated using the formula below:

Compressive strength $=\frac{\text { maximum load }}{\text { coss rectional area of cube }}$

\subsection{Compressive Strength}

The compressive strengths of each brand were determined at ages of 7 days, 14 days, 21 days and 28 days by following GB/T 50081(2002) standard requirements.

A load- factor of $10 \mathrm{kN}$ was applied during the cubes compression strength test. The compression tests were conducted with Compression Testing Machine from Ghana Highway Authority.

The concrete compressive strength after 28days of all cements types were defined as the strength obtained from standard cubes 150mm in accordance with GBC 7225-6: 2012

A computer software Minitab was used to analyse the experimental data. Computing the statistical information of the data like the mean, standard deviation, $\mathrm{p}$-values and $\mathrm{f}$-values of variable were presented.

\subsection{Validity of test results}

All aggregates for the test were air-dried under normal room temperature and that the particle distribution of the aggregate used for mixing is a true representation of the supply. Aggregates used for mixing were free from organic impurities. Mixing, filling of moulds and compaction times were approximately uniform for all cubes.

\subsection{Results and Discussions}

\subsection{Results}

In using concrete for project and its quality control, strength is the property normally specified, this is because, comparing it to most other concrete properties, testing the strength of cement is comparatively easy (Kamran, 2015).

The data presented in this section of the study was obtained from the Laboratory test results on the various samples made from nine (9) different brands of Ordinary Portland Cement used my Ghanaian construction industry. Different brands of cement were chosen to ascertain the effect of the cement brand on the compressive strength of concrete. The independent variable is the cement brands and the compressive strengths were the dependent variables. Table 2 below show the average result obtained from the 7 days, 14days, 21days and 28days of test.

However, Cement Type A (42.5R), E (42.5R), F (42.5R), G (42.5R, J (32.5R), and H (32.5R) used in the concrete production, when tested on the seventh day met the least requirement of compressive strength of concrete in seven days which should not be less than 14N/mm² according to BSEN197-1:2011. The following cement brands 
could not meet the BSEN197-1:2011 minimum standard within the seven days; B (32.5R), C (42.5N) and D (32.5R). Their compressive strength at age 7 was below $14 \mathrm{~N} / \mathrm{mm}^{2}$

One of the amazing discovery is the strength development of cement type $\mathrm{J}$. Though $\mathrm{J}$ is grade $32.5 \mathrm{R}$ Cements, it has better compressive strength development than most grade 42.5R cements. It is only Cement Type $\mathrm{E}$ which has better compressive strength than it on the 14days and 28days. At the end of the 28days in accordance with GBC 2012- 7.2.2.1.2, it was only Cement Type E grade 42.5R which has a better compressive strength than Cement Type J which is grade 32.5R. In general, there are four best Cement brand of Portland Cement among the nine cement brand and grade used for the experiment. These brands were; Cement type E grade 42.5R with approximate compressive strength at 28 days age as $24 \mathrm{~N} / \mathrm{mm}^{2}$, Cement type A grade $42.5 \mathrm{R}$ with approximate compressive strength at 28 days age as $23 \mathrm{~N} / \mathrm{mm}^{2}$, Cement type J grade $32.5 \mathrm{R}$ with approximate compressive strength at 28days age as $23 \mathrm{~N} / \mathrm{mm}^{2}$ and Cement Type $\mathrm{H}$ grade $32.5 \mathrm{R}$ with approximate compressive strength at 28 days age as $21 \mathrm{~N} / \mathrm{mm}^{2}$. The result does not agree with Adewole, et al. (2015) who have found out that, using a cube side of $150 \mathrm{~mm}$ to produced concrete for test; the compressive strength of the cube at the age of 28 days when tested must vary between $15 \mathrm{~N} / \mathrm{mm}^{2}$ to $80 \mathrm{~N} / \mathrm{mm}^{2}$ since not all the cement brands meet that requirement.

Table 2: Summary of Compressive Strength of the Nine Cements Brands

\section{TESTS ON CEMENT}

\begin{tabular}{|c|c|c|c|c|c|c|}
\hline \multirow[b]{2}{*}{$\mathbf{S} / \mathbf{N}$} & \multirow[b]{2}{*}{ Cement Type } & \multirow[b]{2}{*}{ Grade } & \multicolumn{4}{|c|}{ Average compressive strength $\left(\mathrm{N} / \mathrm{mm}^{2}\right)$} \\
\hline & & & 7days & 14days & 21days & 28days \\
\hline 1 & A & $42.5 \mathrm{R}$ & 19.13 & 19.54 & 19.67 & 23.22 \\
\hline 2 & B & $32.5 \mathrm{R}$ & 10.34 & 12.40 & 15.79 & 14.10 \\
\hline 3 & $\mathrm{C}$ & $42.5 \mathrm{~N}$ & 13.93 & 16.12 & 18.28 & 18.31 \\
\hline 4 & $\mathrm{D}$ & $32.5 \mathrm{R}$ & 11.07 & 13.22 & 14.22 & 15.43 \\
\hline 5 & $\mathrm{E}$ & $42.5 \mathrm{R}$ & 18.84 & 21.77 & 22.00 & 23.58 \\
\hline 6 & $\mathrm{~F}$ & $42.5 \mathrm{R}$ & 15.28 & 17.18 & 17.23 & 18.73 \\
\hline 7 & G & $42.5 \mathrm{R}$ & 17.13 & 17.96 & 19.61 & 19.66 \\
\hline 8 & $\mathrm{H}$ & $32.5 \mathrm{R}$ & 14.67 & 15.72 & 19.93 & 20.47 \\
\hline 9 & $\mathrm{~J}$ & $32.5 \mathrm{R}$ & 20.30 & 20.43 & 22.04 & 22.71 \\
\hline
\end{tabular}

\subsection{Data Analysis and Discussion}

Base on general observation from the test carried out on the samples of concrete cubes made with nine brands of Ordinary Portland cement presented in the Table 2 above, it has been identified that the cement brands are in three categories. These categories are presented in Table 3, 4 and 5 below at age 28 days. 
Table 3: The compressive strength of $42.5 \mathrm{R}$ cement grades at 28days age

\begin{tabular}{l|l|l}
\hline Cement Type & Ages 28 (days) & Compressive strength \\
\hline A & 28 & $23.22 \mathrm{~N} / \mathrm{mm}^{2}$ \\
E & 28 & $\mathbf{2 3 . 5 8 N} / \mathbf{m m}^{2}$ \\
F & 28 & $18.73 \mathrm{~N} / \mathrm{mm}^{2}$ \\
G & 28 & $19.66 \mathrm{~N} / \mathrm{mm}^{2}$ \\
\hline
\end{tabular}

Data presented in Table 3 revealed that, the compressive strength of grade $42.5 \mathrm{R}$ cements, were between the ranges of $18.73 \mathrm{~N} / \mathrm{mm}^{2}$ to $23.58 \mathrm{~N} / \mathrm{mm}^{2}$. From the result, cement type F recorded the lowest compressive strength among grade $42.5 \mathrm{R}$ cements that is $18.73 \mathrm{~N} / \mathrm{mm}^{2}$ at the end of 28 days' age. The finding agreed with Adewole, et al. (2015) when they found out that, using a cube side of $150 \mathrm{~mm}$ to produced concrete for test; the compressive strength of the cube at the age of 28 days when tested must vary between $15 \mathrm{~N} / \mathrm{mm}^{2}$ to $80 \mathrm{~N} / \mathrm{mm}^{2}$. The founding also agreed with CivilSir (2015) that for design mix of 1:2:4 (M15), the minimum strength to attain in 28 day's age should be $15 \mathrm{~N} / \mathrm{mm}^{2}$.

There was only one Cement type $(C)$ with grade $42.5 \mathrm{~N}$ and have its compressive strength at the end os 28 days age lower than all the 42.5R and most 32.R, except cement type B grade 32.5R as shown in Table 4 below.

Table 4: The compressive strength of $42.5 \mathrm{~N}$ cement grades at 28 days age

\begin{tabular}{l|l|l}
\hline Cement Type & Ages 28 (days) & Compressive strength \\
\hline $\mathbf{C}$ & 28 & $18.31 \mathrm{~N} / \mathrm{mm}^{2}$ \\
\hline
\end{tabular}

Table 5 below indicates the $32.5 \mathrm{R}$ grades of cement and their compressive strength at 28 days' age from the lowest to the highest.

Table 5: The compressive strength of $32.5 \mathrm{R}$ cement grades at 28days age

\begin{tabular}{l|l|l}
\hline Cement Type & Ages 28 (days) & Compressive strength \\
\hline B & 28 & $14.10 \mathrm{~N} / \mathrm{mm}^{2}$ \\
D & 28 & $15.43 \mathrm{~N} / \mathrm{mm}^{2}$ \\
H & 28 & $20.47 \mathrm{~N} / \mathrm{mm}^{2}$ \\
J & 28 & $22.71 \mathrm{~N} / \mathrm{mm}^{2}$ \\
\hline
\end{tabular}

Analysing the data presented in Table 5 the compressive strength of 32.5R cement grades, was between the ranges of $14.10 \mathrm{~N} / \mathrm{mm}^{2}$ and $22.71 \mathrm{~N} / \mathrm{mm}^{2}$, which is lower than the compressive strength of grade $42.5 \mathrm{R}$ cement. From the Table above Cement Type B recorded the lowest compressive strength of $14.10 \mathrm{~N} / \mathrm{mm}^{2}$ whilst Type J recorded the highest of $22.71 \mathrm{~N} / \mathrm{mm}^{2}$. The strength development of cement brand B does not meet the requirement of CivilSir (2015) which say that for design mix of 1:2:4 (M15), the minimum strength to attain in 28 day's age should be $15 \mathrm{~N} / \mathrm{mm}^{2}$. 


\subsection{Hypothesis Testing}

The Hull Hypothesis state that: there is no significant difference in the compressive strength of concrete made from all the nine brands of cement in Ghana. The result from statistical tools were shows in tables and figure

The test focuses on the two common grades that is grade $42.5 \mathrm{R}$ and grade $32.5 \mathrm{R}$. Since grade $42.5 \mathrm{~N}$ is only one brand but was used in the overall analysis.

\subsection{Differences in Compressive Strength based on ages (days) for each Grade}

The first analysis looked at the different in compressive strength between grade 32.5R and 42.R. Table 6 gives us the statistical result on grade $32.5 \mathrm{R}$ and $42.5 \mathrm{R}$.

Table 6: Differences in Compressive Strength based on ages (days) for each Grade

\begin{tabular}{|c|c|c|c|c|c|c|c|}
\hline Brand & Days & $\mathbf{N}$ & Mean & Std. Dev & Std. Error & F-value & p-value \\
\hline \multirow{5}{*}{$42.5 \mathrm{R}$} & 7 days & 12 & 17.594 & 1.771 & 0.511 & \multirow[t]{5}{*}{7.071} & \multirow[t]{5}{*}{0.001} \\
\hline & 14 days & 12 & 19.104 & 1.997 & 0.576 & & \\
\hline & 21 days & 12 & 19.671 & 1.872 & 0.540 & & \\
\hline & 28 days & 12 & 21.298 & 2.294 & 0.662 & & \\
\hline & Total & 48 & 19.417 & 2.348 & 0.339 & & \\
\hline \multirow{5}{*}{$32.5 \mathrm{R}$} & 7 days & 12 & 14.113 & 4.190 & 1.210 & \multirow[t]{5}{*}{3.388} & \multirow[t]{5}{*}{0.026} \\
\hline & 14 days & 12 & 15.442 & 3.369 & 0.973 & & \\
\hline & 21 days & 12 & 17.998 & 3.640 & 1.051 & & \\
\hline & 28 days & 12 & 18.180 & 3.724 & 1.075 & & \\
\hline & Total & 48 & 16.433 & 4.018 & 0.580 & & \\
\hline
\end{tabular}

The results in Table 6 clearly shows a significant different in grade 32.5R and that of grade $42.5 \mathrm{R}$ with respective $\mathrm{F}$ - value of 3.388 and 7.071. The F-value of 7.071 confirmed that grade 42.5R in general develops better compressive strength that grade $32.5 \mathrm{R}$ when used in concrete production. Figure 1 illustrate how the grade $42.5 \mathrm{R}$ and $32.5 \mathrm{R}$ develop their strength within the 28 days. 


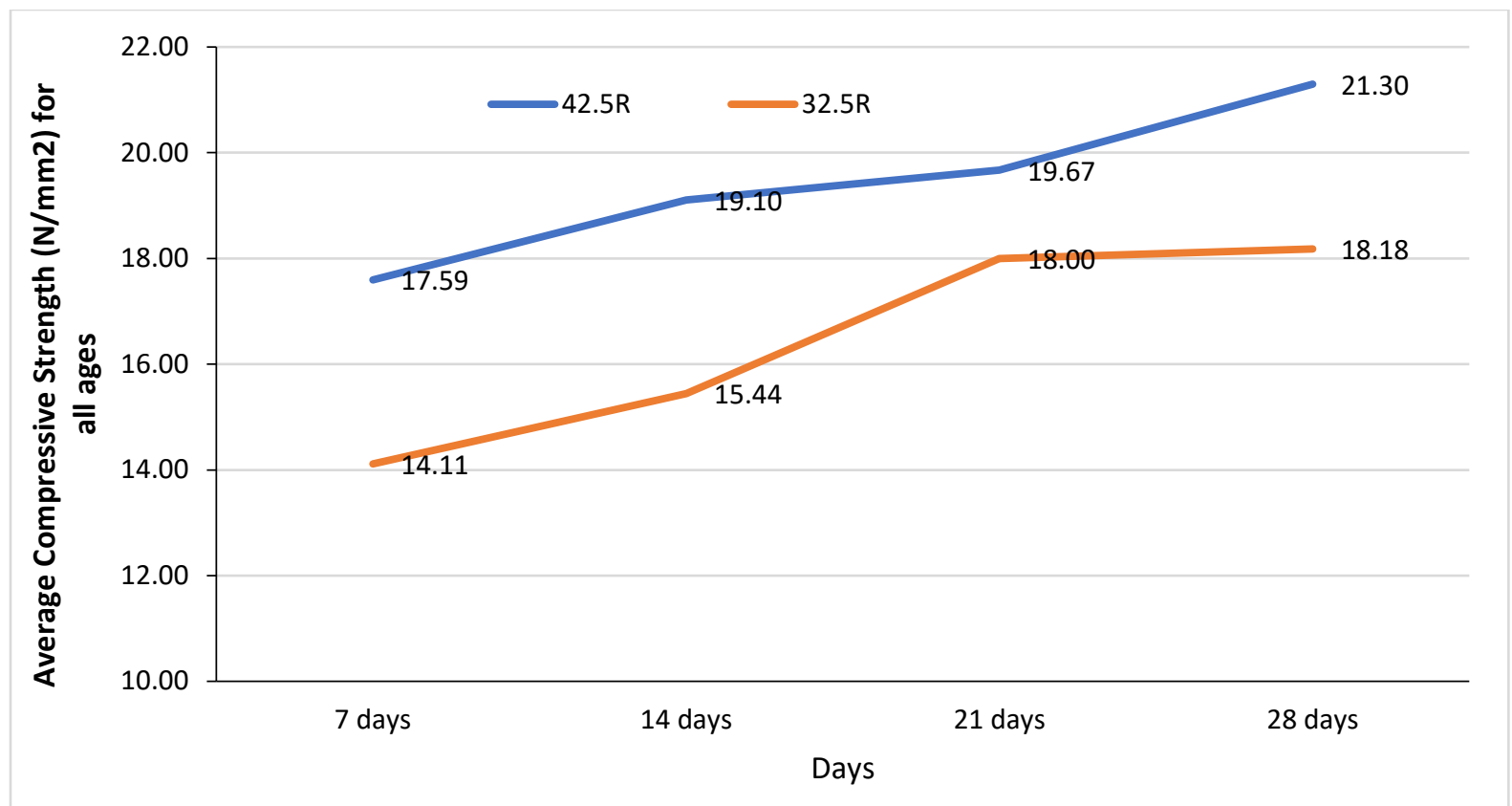

Figure 1: Average Compressive Strength (N/mm2) for Grades (42.5R and 32.5R)

Figure 1 shows that the average compressive strength of grade 32.5R fall below the expected minimum value at seven days; which according to BSEN197-1:2011 should not be below 14N/mm². The average compressive strength for grade $42.5 \mathrm{R}$ met the 7 days age minimum requirement.

3.5 Multiple Comparisons of the Difference between Compressive Strength of Cement Brands for Grade 32.5R

Further analysis as presented in Table 7 presents a clear difference in compressive strength among even the same grade of Cements.

Table 7: Multiple Comparisons of the Difference between Compressive Strength of Cement Brands for Grade 32.5R

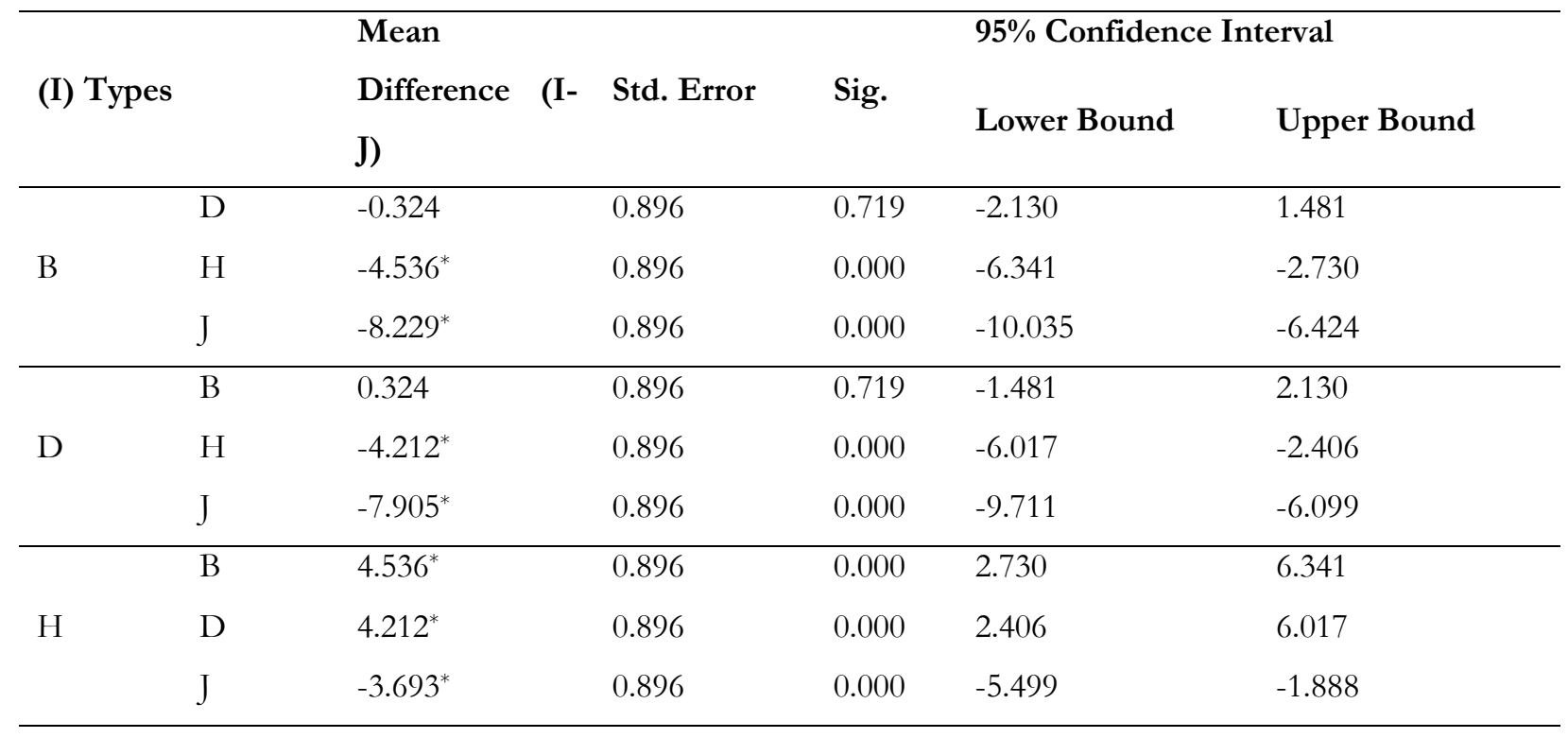




\begin{tabular}{|c|c|c|c|c|c|}
\hline B & $8.229^{*}$ & 0.896 & 0.000 & 6.424 & 10.035 \\
\hline $\mathrm{D}$ & 7.905* & 0.896 & 0.000 & 6.099 & 9.711 \\
\hline $\mathrm{H}$ & 3.693 & 0.896 & 0.000 & 1.888 & 5.499 \\
\hline
\end{tabular}

*. The mean difference is significant at the 0.05 level.

From Table 7, there is a clear difference in compressive strength between Cement Type B as compared to Type H and $J$ with mean difference of -4.536 and -8.229 respectively. There was a significant difference in compressive strength between Cement Type D compared to $\mathrm{H}$ and J with the significant value of 0.000 and mean difference of -4.212 and -7.905 respectively. The cement type $\mathrm{H}$ also has its compressive strength different far from Cement Type B, D and J and J has better compressive strength than B and D. From the Table above, the most significant difference in compressive strength of the Cement Types exist when comparing Cement Type J to B and D with mean difference of 8.229 and 7.905 respectively.

3.6 Multiple Comparisons of the Difference between Compressive Strength of Cement Brands for Grade 42.5R

The research tries to compare the compressive strength of grade 42.5R. Table 8 below shows the mean difference in the compressive strength of the cement types at significant level of 0.05 .

Table 8: Multiple Comparisons of the Difference between Compressive Strength of Cement Brands for Grade 42.5R

\begin{tabular}{lllllll}
\hline \multirow{2}{*}{ (I) Brand of Cement } & Mean Diff. (I-J) & Std. Error & p-value & 95\% Confidence Interval \\
& & & & LB & UB \\
\hline A & E & -1.153 & 0.684 & 0.099 & -2.531 & 0.226 \\
& F & $3.243^{*}$ & 0.684 & 0.000 & 1.864 & 4.621 \\
& G & $1.800^{*}$ & 0.684 & 0.012 & 0.422 & 3.178 \\
\hline E & A & 1.153 & 0.684 & 0.099 & -0.226 & 2.531 \\
& F & $4.395^{*}$ & 0.684 & 0.000 & 3.017 & 5.773 \\
& G & $2.953^{*}$ & 0.684 & 0.000 & 1.574 & 4.331 \\
\hline F & $-3.243^{*}$ & 0.684 & 0.000 & -4.621 & -1.864 \\
& E & $-4.395^{*}$ & 0.684 & 0.000 & -5.773 & -3.017 \\
& G & $-1.443^{*}$ & 0.684 & 0.041 & -2.821 & -0.064 \\
\hline G & $-1.800^{*}$ & 0.684 & 0.012 & -3.178 & -0.422 \\
& E & $-2.953^{*}$ & 0.684 & 0.000 & -4.331 & -1.574 \\
\hline *. The mean difference is significant at the 0.05 level. & & 0.041 & 0.064 & 2.821 \\
\hline
\end{tabular}

From Table 8, there is significant difference in compressive strength when comparing Cement Brand, A to that of E, F and G. A clear significant exist when comparing Cement Brand, A to F and G with mean difference of 3.243 and 1.800 respectively. The p-value of 0.000 for both Cement Brand $F$ and $G$ as compared to $E$ with a mean difference of 4.395 and 2.953 respectively, shows a significant difference in their compressive strength. Comparing 
Cement Brand $\mathrm{G}$ to Brand $\mathrm{A}, \mathrm{E}$ and $\mathrm{F}$ shows that there is a significant difference in their compressive strength based on the mean difference of $-1.800,-2.953$ and 1.443 with p-value of $0.012,0.000$ and 0.041 respectively.

Amazingly at the end of the 28 days two of the grade $32.5 \mathrm{R}$ approximately have better compressive strength like that of grade $42.5 \mathrm{R}$ based on individual compressive strength. These approximate individual compressive strengths are shown in Figure 2.

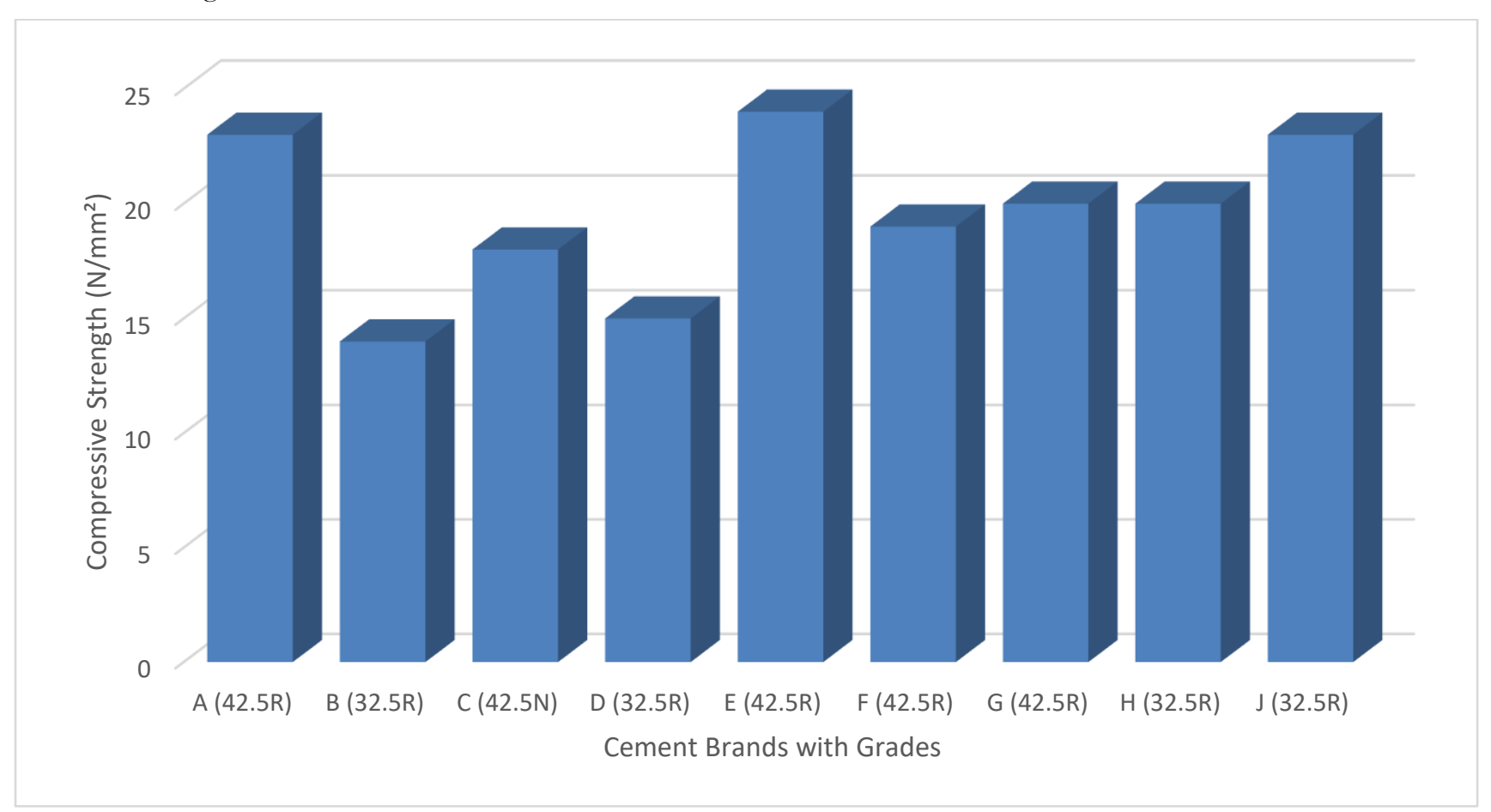

Figure 2. Approximate 28days Compressive Strength of the Nine Cement Brands

In general, there exist a significant difference in the compressive strength of concrete made from the nine brands of cement from Ghana. Therefore, the Hull Hypothesis of no significant difference has been rejected

\section{Conclusion}

Quality assurance of building materials is very crucial in order to build strong, durable and cost effective buildings (Savitha,2012). So, when putting up a structure, selection of building materials should be done well for them to fulfil the expected functions from them.

It can be concluded that most of the Portland Cement with grade 32.5R do not met the minimum compressive strength value within 7days. It was noted that Ordinary Portland cement brand E of grade 42.5R has the highest compressive strength after 28 days. One major amazing thing is that Ordinary Portland Cement Brand H and J of grade 32.5R have better compressive strength at the end of the 28days age than Ordinary Portland Cement Brand G, F and C of grade 42.5R. The study discovered that the Ordinary Portland Cement Brand C of grade 42.5R and brand $\mathrm{B}$ of grade $32.5 \mathrm{R}$ have the lowest compressive strength after 28days. This finding agreed with research conducted by Kazeem, et al (2014) in Nigeria which through a comparative study of compressive strength of concrete made with grade $42.5 \mathrm{~N}$ and $32.5 \mathrm{~N}$ revealed difference compressive strength value at 28 days' age. 
Hodhod and Abdeen (2010) research from Egypt has also supported the findings, they have conducted a relative study on the properties of concrete made with OPC grades 52.5, 42.5 and 32.5 and reported differences in their properties.

The difference in the same grade compressive strength may be attributed to the brand type and the Chemical composition of the cements. Since there is accepted percentages of chemicals composition in Ordinary Portland cement for its proper functioning in concrete as said by Salih et al. (2020) who believed that the chemical composition and the physical properties of ordinary Portland cement can significantly affect its compressive strength.

If there is the need to use any of grade $32.5 \mathrm{R}$ for concrete work, investigation must be carried out since some of the grade $32.5 \mathrm{R}$ cement met the minimum requirement. Also, there must be thorough investigation into the chemical composition of all Ordinary Portland Cements used in Ghana to see if the chemical compositions have any effect on concrete made with these ordinary Portland cements.

\section{References}

Adewole, K.K., Ajagbe, W.O. and Arasi, I.A. (2015) Determination of Appropriate Mix Ratios for Concrete Grades Using Nigerian Cements. Leonardo Electronic Journal of Practices and Technologies, 26, 79-88.

Ali, M. S., Khan, I. A. and Hossain, M. I. (2008). Chemical Analysis of Ordinary Portland Cement of Bangladesh. Chemical Engineering Research Bulletin 12 (2008) 7 -10.

Anand, P. (2016). Compressive Strength of Concrete and Concrete Cube. Accessed: [Online] Available from: https://civildigital.com/compressive-strength-concrete-concretecubes/.

Bediako, M., \& Amankwah, E. O. (2015). Analysis of Chemical Composition of Portland Cement in Ghana: A Key to Understand the Behavior of Cement. Advances in Materials Science and Engineering, 2015, 1-5. doi:10.1155/2015/349401.

BS 882 (1992) Specification for Aggregates from Naturanl Sources for Concrete. British Standard. BS 8500-2:(2002) - Specification for constituent materials and concrete. British Standard. BS EN 206-1(2000) - Specification, performance, production and conformity. British Standard. BS 882 (1992) Specification for Aggregates from Naturanl Sources for Concrete. British Standard. BS EN 197-1. 2011. Composition, Specification and Conformity criteria for common cements. BSI Standards Publication.

CivilSir, (2021). How much cement sand \& aggregate required for M15 concrete? [Online] Available from: https://civilsir.com/how-much-cement-sand-aggregate-required-for-m15-concrete/.

De Schutter, G., \& Lesage, K. (2018). Active control of properties of concrete: a (p)review. Materials and Structures, 51(5). doi:10.1617/s11527-018-1256-2.

GB/T 50081-(2019). Standard for Test Method of Mechanical Properties on Ordinary Concrete; Ministry of Construction of the People's Republic of China and Quality Supervision Inspection and Quarantine of the People's Republic of China: Beijing, China, 2002..

Ghana Building Code (2012). Compressive strength 7.16.2.3. Ghana Standard. 
Hasan, M. M. and Kabir, A. (2011). Prediction of Compressive Strength of Concrete from early Age Test

Result. $4^{\text {th }}$ Annual paper Meet and $1^{\text {st }}$ Civil Engineering congress. December 22-24 Ahaka Bangladesh.

Hemali, P. (2018). Factors that can affect the Strength of Concrete. [Online] Available from:

https://gharpedia.com/blog/factors-that-affect-strength-of-concrete/.

Hewlett, P. and Liska, M. (2019). Chemistry of Cement and Concrete. Butterworth-Heinemann, 2019.

Hodhod, A. H and Abdeen, M. A. M. (2010). Experimental comparative and numerical predictivestudies on strength evaluation of cement types: effects of specimen shape and type of sand. Scientific research engineering, 2: 559-572.

Kamran N. (2015). CM425-Concrete Technology. University of Washington, Winter Quarter. http//courses.washington.edu//cm425/aggregate.pdf. Accessed: 6/04/21, pp. 4.

Kazeem, K. A., Festus, A. O and Hamzat, H., (2014). Effect of Nigerian Portland-Limestone cement grades on concrete compressive strength. International Journal of Civil, Environmental, structural, Construction and Architectural Engineering. (11): 1140-1143.

Khoury, G. A. (1992). Compressive strength of concrete at high temperatures: a reassessment. Magazine of Concrete Research, 44(161), 291-309. doi:10.1680/macr.1992.44.161.291.

Lee, T., Lee, J., Choi, H. and Lee, Dong-Eun (2020). The Effects of Fineness and TEA-Based Chemical.

Admixture on Early Strength Development of Concrete in Construction Site Applications. Materials 2020, 13, 2027; doi: 10.3390/ma13092027.

Mathur, R., Misra, A. K and Goel, P. (2014). Strength of concrete vs Grades of cement, Central Road research Instiute, New Delhi. http://www.nbmcw.com/articles/concrete/ 25796-strength-ofconcrete vs-grades-of- cement html. assessed on 25th April, 2014.

Manzano, H., Durgun, E., Abdolhosseine- Qomi, M. J., Ulm, F.-J., Pellenq, R. J. M., and Grossman, J. C. (2011). Impact of Chemical Impurities on the Crystalline Cement Clinker Phases Determined by Atomistic Simulations. Crystal Growth \& Design, 11(7), 29642972. doi:10.1021/cg200212c.

Ni, H.-G., \& Wang, J.-Z. (2000). Prediction of compressive strength of concrete by neural networks. Cement and Concrete Research, 30(8), 1245-1250. doi:10.1016/s0008-8846(00)00345-8.

Salih, M. A., Aldikheeli, M. R., \& Shaalan, k A. (2020). Evaluation of factors influencing the compressive strength of Portland cement statistically. IOP Conference Series: Materials Science and Engineering, 737, 012059. doi:10.1088/1757-899x/737/1/012059.

Savitha, A. (2012) Importance of Quality Assurance of Materials for Construction Work. Building Materials Research and Testing Division, 1-5. 